\title{
Exportaciones de capital y grupos inversores: las inversiones francesas en la Argentina, 1880-1914.
}

\author{
Andrés M. Regalsky \\ Instituto Torcuato Di Tella. CONICET. \\ Buenos Aires
}

Entre 1880 y 1914 la Argentina experimentó un rápido crecimiento económico, que contó con una elevada participación de capitales extranjeros. En su composición por origen, las inversiones francesas ocuparon un lugar muy destacado, detrás de las británicas. En este trabajo realizamos un ensayo de caracterización de los grupos que animaron dichas inversiones, fundamentando su adopción como eje de análisis, sobre otros enfoques utilizados en los estudios de este tipo. Seguidamente examinamos la formación y características de los grupos inversores franceses en la Argentina, atendiendo a su composición y cuadro de intereses, así como a los patrones de inversión, gestión y rentabilidad que los distinguieron. De esta manera aportamos a la comprensión de la dinámica interna de las inversiones y de su lógica en el escenario local, marcada por una ambigua relación, nutrida de expectativas pero también de tensiones, con las élites locales a todo lo largo del período.

Entre 1880 y 1914 la Argentina experimentó un rápido crecimiento económico, uno de los mayores de su época y, sobradamente, el más importante de toda su historia económica. Este crecimiento, al igual que el de otros países de "reciente asentamiento", estuvo basado en la puesta en explotación de una enorme extensión de tierras fértiles recientemente ocupadas y la constitución de una moderna economía exportadora de productos agropecuarios. ${ }^{1}$

En este proceso las inversiones extranjeras desempeñaron un papel de gran relevancia. Por su magnitud, como por el carácter estratégico de los sectores a los que se dirigió y su repercusión local, no admite comparación con ningún otro período (véase el cuadro 1). Así pues, el quantum ingresado entre 1880 y 1914 superó con creces la dotación inicial de capital existente en el país, los flujos de inversión anuales fueron a menudo mayores que los de origen nacional y al finalizar la etapa, los pasivos externos equivalían a la mitad del capital fijo del país (tierras, ganado, "usinas", construcciones, infraestructura). ${ }^{2}$

1 Cortés Conde, Roberto, y Ezequiel Gallo: La formación de la Argentina moderna, Buenos Aires, 1967, y La Argentina conservadora, Buenos Aires, 1972.

2 CEPAL, Comisión Económica para América Latina, El desarrollo económico argentino, Santiago de Chile, 1958 (mimeo), vol. V, cap.2. 
En su composición por origen el predominio de los capitales británicos fue evidente a lo largo de todo este período. No obstante, la participación de los capitales de otros orígenes fue también significativa y creciente. Entre ellos, el caso de los capitales franceses merece destacarse especialmente. En primer término, por sus dimensiones relativas: ocuparon el segundo lugar permanentemente, y llegaron a representar un $20 \%$ de las inversiones extranjeras totales en vísperas de la Primera Guerra Mundial. En segundo termino, presentaron una estructura bien diversificada hacia los principales rubros de inversión de la época (ferrocarriles e infraestructura, sector público y finanzas), y estuvieron asociados, hasta fines del siglo XIX, a una presencia comercial equiparable a la de Gran Bretaña. A pesar de ello han sido muy poco estudiados (cuadro 2).

En diversos trabajos anteriores hemos tratado de avanzar en el análisis de la intervención de los capitales franceses en la Argentina, a través de sucesivos estudios de casos. ${ }^{3}$ En este texto pretendemos centrarnos en las características generales de los grupos inversores que activaron la afluencia de estos capitales, vale decir en aquellas coaliciones de intereses que captaban los recursos del público en los mercados financieros, decidían sobre su destino ulterior y mantenían el control de las empresas creadas. El análisis de los grupos inversores ha sido muy poco utilizado en los trabajos sobre inversiones extranjeras en la Argentina. Como se examinará más adelante, resulta notoria la prevalencia de estudios por sectores, o en el mejor de los casos, centrados en las empresas individuales. La pertinencia del enfoque que proponemos, y su conexión con otros conceptos empleados en la literatura sobre el tema, serán el objeto de la primera sección de este trabajo.

En la segunda sección analizaremos, en sus grandes líneas, la evolución de los principales grupos inversores franceses en la Argentina. A partir de los datos recopilados en nuestras investigaciones sobre el tema, procuraremos delinear algunas de las características destacables de estos grupos en cuanto su composición y el cuadro de intereses que articularon

3 Véanse Regalsky, Andrés: "Exportaciones de capital hacia los países nuevos: los bancos franceses y las finanzas públicas argentinas, 1881-1887”, Revista de Historia Económica, Madrid, 1987; "Finanzas, inversiones y política estatal en el siglo XIX: las inversiones francesas en los ferrocarriles argentinos, 1887- 1900", Siglo XIX. Revista de Historia, Monterrey- México, III:5, enero-junio 1988, págs. 125-166; "Capital extranjero y finanzas provinciales en la Argentina: los empréstitos franceses de la década de 1880", Cuadernos de Historia Regional, 12, Universidad Nacional de Luján, 1988, págs. 25-50; "Foreign Capital, Local Interests and Railway Development in Argentina: French Investments in Railways 1900-1914", Journal of Latin American Studies, 21:3, Cambridge, Oct. 1989, 425-452; y "La Compañía Francesa de Ferrocarriles de Santa Fe", Archivo Fotográfico del Ferrocarril de Santa Fe, Buenos Aires, 1992. 


\section{CuAdro 1}

LOS CAPITALES EXTRANJEROS EN LA ARGENTINA, 1890-1913 (EN MILLONES DE PESOS ORO)

\begin{tabular}{lcc} 
& Total al & Total al \\
& $31-12-90$ & 31-12-13 \\
\hline Empréstitos y cédulas & 451.4 & 903 \\
Ferrocarriles & 345.0 & 1.215 \\
Miscelánea & 95.0 & 1.187 \\
\hline Total & 891.9 & 3.305
\end{tabular}

Fuentes: cálculos basados en Williams, John: The Argentine International Trade under Inconvertible Paper Money, Cambridge (Massachusets), 1920, págs. 100-103; Ministerio de Hacienda (Argentina), Memoria, (1890) pág. 130, (1891) págs. 12 y 208, y (1893) págs. 147-156; Peña, Juan B.: Compilación de leyes, decretos, resoluciones, notas y contratos sobre la Deuda Pública Nacional, Buenos Aires, 1907, págs. 1165-1195; Dirección General de Ferrocarriles, Estadística de los ferrocarriles en explotación, Buenos Aires, (1892) págs. 134-135, (1893) págs. 252-255, (1913) págs. 380381, 424-427 y (1914) págs. 468-476; Phelps, Vernon L.: The Economic Position of Argentina, Philadelphia, 1938, y Martínez, Alberto B.: Annuaire économique et financier de la République Argentine, Barcelona, 1913.

\section{CUADRO 2}

LOS CAPITALES FRANCESES EN LA ARGENTINA, 1890 Y 1913 DISTRIBUCIÓN SECTORIAL EN VALORES NOMINALES

\begin{tabular}{|c|c|c|c|c|}
\hline & $\begin{array}{c}1890 \\
\text { millones \$ oro }\end{array}$ & $\%$ & $\begin{array}{c}1913 \\
\text { millones \$ oro }\end{array}$ & $\%$ \\
\hline Empréstitos & 34.9 & 46 & 282.5 & 45 \\
\hline Ferrocarriles & 32.3 & 43 & 124.4 & 20 \\
\hline Hipotecarias & 7.6 & 10 & 152.0 & 24 \\
\hline Bancos & 1.0 & 1 & 27.6 & 4 \\
\hline Puertos & - & - & 25.1 & 4 \\
\hline Otros & - & - & 17.6 & 3 \\
\hline Total & 75.8 & 100 & 629.1 & 100 \\
\hline Capitales ingleses & 686.2 & & 1610.0 & \\
\hline
\end{tabular}

Fuentes: ídem cuadro 1, y Finance-Univers, Annuaire 1914. Valeurs français et étrangers cotés en France, Paris, 1914; Garzon, Eugène: L’Amérique Latine: République Argentine, Paris, 1913; Ministère de l'Economie et des Finances, Archives Economiques et Financières (MEF-AEF), B31.329 (Etat des capitaux français en 1911). 
en su seno, así como a patrones de inversión, gestión y rentabilidad, que hacen a la lógica de su comportamiento. ${ }^{4}$ La posibilidad de discernir estrategias de inversión por parte de estos grupos será discutida en la conclusiones, como un aporte a la comprensión no solo de la dinámica intrínseca de las inversiones, sino también del papel desempeñado por los capitales franceses en el escenario local, y de la ambigua relación (cruzada de expectativas, pero también de tensiones) que mantuvieron las élites locales con el capital extranjero en la Argentina de este período.

\section{El concepto de "grupo inversor". Algunas consideraciones preliminares}

Nuestra propuesta de centrar el estudio en los actores o agentes económicos involucrados en el flujo de los capitales franceses a la Argentina, nos impone la necesidad de dar algunas precisiones sobre el concepto elegido como clave, el de "grupo inversor". La mera enunciación de esos términos pone de manifiesto dos cuestiones: nuestra ubicación en el plano de los inversores, los que toman las decisiones de inversión, en contraposición a las propias inversiones consideradas en sí mismas como objeto de la investigación. Al mismo tiempo, que estamos aludiendo a actores colectivos, "grupos" de inversores, y no a actores individuales.

En los enfoques centrados en inversores individuales suele operar la idea "heroica" de un empresario "innovador" aislado (con reminiscencias obviamente schumpeterianas), que por obra de su intuición para los negocios, su esfuerzo, astucia y capacidad logra llevar adelante toda una serie de inversiones ligadas a una empresa o conglomerado. Esta figura, presente otrora en los estudios de la historia industrial o de empresas (business history), omite a nuestro juicio el hecho, tan de relieve en análisis recientes, de que ese empresario opera en una red de vinculaciones personales y comerciales, y que parte de su éxito reside en saber recurrir a ellas de una manera hábil y eficaz. El concepto de economía "de red", utilizado especialmente para explicar la operatoria moderna de empresas y conglomera-

4 En este punto, el de la identificación y comprensión de la lógica de los actores, ver los análisis que desde la historia política ha efectuado Guerra, François-X.: México.Del Antiguo Régimen a la Revolución, México, 1988; y "Pour une nouvelle histoire politique: acteurs sociaux et acteurs politiques", Structures et cultures des sociétés ibéro-américaines, au-delà du modèle socio-économique, Paris, 1990, págs. 245-260. 
dos, se encuentra también subyacente en algunos análisis destinados a explicar la emergencia de los principales conglomerados o "grupos" empresarios en la Argentina de fines del siglo pasado. ${ }^{5}$

$\mathrm{Al}$ referirnos a los "grupos", entendemos que su acción trasciende la figura del individuo al frente de una empresa, y esto vale para decir que su actividad empresarial y sus decisiones estratégicas de inversión pueden ser mejor comprendidas en un contexto de alianzas, familiares y extrafamiliares, que desde muy antigua data están en el origen de muchos de los participantes, y también otras más recientes forjadas en el mismo devenir de los negocios. Aludir a "grupos" implica penetrar en la dimensión "informal" de la financiación de empresas, tanto bancarias como industriales o de cualquier otro objeto, que requirieron el concurso de una amplia red de participantes, para lo cual se ponían en juego las conexiones familiares y comerciales de que disponían los empresarios en cuestión.

Este concepto de "grupo inversor" guarda analogías con diversos términos utilizados en los análisis del campo empresario, y sobre todo de las estrategias de negocios, que se enmarcan en estudios contemporáneos de los procesos de industrialización y "ajuste" estructural de la Argentina y otros países latinoamericanos. Así encontramos el uso de términos tales como "grupos", "grupos económicos y empresariales", o incluso "grupos económicos de inversión". Aspiazu, Basualdo y Khavisse definen al "grupo económico" como un "conjunto de empresas con una dirección única...en numerosos sectores de la economía", aludiendo por una parte a su caracter de "conglomerado" pero, también, al hecho de que la lógica de la conducción empresarial trasciende el marco de cada empresa en cuestión. ${ }^{6}$

5 Marichal, Carlos: "La gran burguesía comercial y financiera de Buenos Aires, 1860-1914: anatomía de cinco grupos", 1982 (mimeo); Barbero, María I.: "Grupos empresarios, intercambio comercial e inversiones italianas en la Argentina. El Caso de Pirelli (1910-1920)", Estudios Migratorios Latinoamericanos, 15-16, 1990, págs. 311-341. Sobre la economía de red, Green, Raúl, y R. Dos Santos: "Economía de red y reestructuración del sector agroalimentario", Desarrollo Económico, 126, jul.-sept. 1992 y Moutoukias, Zacarías: "Réseaux personnels et autorité coloniale: Les négociants de Buenos Aires au XVIIIè siècle", Annales ESC, 4-5, juillet-octobre 1992, págs. 889-915.

6 Aspiazu, D.; E. Basualdo, y M. Khavisse: El nuevo poder económico en la Argentina de los años 80, Buenos Aires, 1986. Para el área latinoamericana, ver Gálvez, J., J. y J. Tybout, "Microeconomic Adjustments in Chile during 1977-81: The Importance of Being a Grupo", World Development, 13:8, 1985, págs. 969-994, y sobre todo Leff, Nathaniel: "Industrial Organisation and Entrepreneurship in the Developping Countries: The Economic Groups", Economic Development and Cultural Change, 26:4, 1978, págs. 661-675, que es tal vez la reflexión más importante sobre este tipo de organización, así como Fligstein, N., y P. Brantley: "Bank control, Owner control or Organisational Dynamics: Who Controls the Large Modern Corporation?", American Journal of Sociology, 98:2, 1992, págs. 280-307, sobre la corporación norteamericana. 
Por su parte, Quiroz y Mushammer se refieren a los grupos como los ámbitos donde se generan las inversiones, que dan cuenta de las empresas y participaciones en las que dichos grupos aparecen involucrados, aunque por otra parte restringen la significación del concepto a la dimensión "informal" de la financiación (obtención de fondos que no pueden ser captados en el mercado "formal" de capitales). ${ }^{7}$ Esta restricción no parece funcionar en los casos que nos toca analizar, donde dichos grupos actúan como tales precisamente para canalizar fondos de los mercados "formales" de capitales.

Los estudios sobre la historia de las inversiones extranjeras en la Argentina han adoptado por lo general el enfoque contrapuesto de tomar a la empresa como unidad de análisis. Dichos estudios, en su mayor parte sobre las inversiones británicas, han tendido a eludir así un análisis centrado en los grupos de inversión que, sobre todo en los de ese origen, se tornaba dificultoso por la naturaleza más heterogénea y compleja de los participantes. Esto a su vez ha suscitado otros problemas y limitaciones. Por un lado, en la evaluación de la rentabilidad de las inversiones, que exige definir quiénes son considerados los inversores. El estudio global de los dividendos ha colocado de hecho en el centro del análisis al conjunto de individuos para los que la inversión era en realidad "de cartera", orientada a la búsqueda de un mayor rendimiento, pero que carecían de participación en la gestión efectiva de los fondos. Por otra parte, los estudios individualizados de las empresas, si bien han permitido un análisis más rico de los avatares experimentados por las inversiones extranjeras en el país receptor y de los factores que influyeron en sus resultados, quedan encapsulados sin un hilo conductor que permita ligar esos casos con la evolución general de las inversiones, ni explicar la lógica de decisiones que trascendían muchas veces a las empresas en cuestión. ${ }^{8}$

Solo los trabajos sobre empréstitos públicos se han focalizado en un tipo de actores como el que nos interesa: los banqueros y financistas que intervenían en las negociaciones con los gobiernos de los países receptores. Se trata del tipo más característico de "inversiones indirectas", pero paradójicamente, donde los actores tenían a su cargo decisiones que involucraban a todo el proceso de inversiones. Aún en estos casos, los actores aparecen corporizados en firmas individuales que participan en negocios

7 Quiroz, Alfonso: Banqueros en conflicto. Estructura financiera y economía peruana, 18841930, Lima, 1990.

8 Lewis, Colin: British Railways in Argentina, 1857-1914. A Case Study of Foreign Investment, Londres, 1983. 
puntuales, acotados en el tiempo y el espacio, y sin elementos de continuidad que permitan delinear lo que podríamos llamar las estrategias de inversión. ${ }^{9}$ Más recientemente, autores británicos han puesto su atención en aquellos elementos de la comunidad de negocios de ese país que tenían un alto grado de control sobre las empresas creadas en el exterior. Así pues, Chapman ha llegado a utilizar el término "grupos inversores", aunque restringido a ciertos operadores (las antiguas "trading companies"). Jones ha realizado, en ese sentido, los estudios más acabados sobre el agrupamiento de estos inversores y su configuración de intereses. ${ }^{10}$

Últimamente, el enfoque "chandleriano" de la nueva "business history" ha alimentado más bien el enfoque anterior, centrado en las empresas. Si bien lo ha hecho en el marco de nuevas temáticas de estudio, que permiten un conocimiento más rico de la dimensión organizativa, tiende a tropezar con las dificultades ya señaladas, puestas en evidencia, en el caso británico, por la inestabilidad y vida efímera de las empresas hasta 1914, como también por la existencia de tomadores de decisiones fundamentales desde afuera de la estructura formal que se ha querido analizar. Desde ese ángulo, el concepto de "free standing companies" es en este momento objeto de discusiones. ${ }^{11}$

El enfoque que proponemos se nutre, en cambio, de una respetable tradición en la historiografía francesa, referida a buena parte de los actores que tratamos de abordar: los bancos y grupos financieros. Estudios clásicos como el de Luthy sobre la banca protestante y otros de historias de empresas, han mostrado la importancia de las redes de alianzas familiares y extra-

9 Entre los autores ingleses, Jones, Charles: "European Bankers and Argentina, 1880-90", Working Papers 3. Business Imperialism Series, Cambridge, 1972 y Platt, D. C. M.: "Foreign Finance in Argentina from the First Half-Century of Independence", Journal of Latin American Studies, 15:1, 1983, págs. 23-47. Entre los argentinos, Amaral, Samuel: "El empréstito de Londres de 1824", Desarrollo Económico, 92, 1984, págs. 559-588.

10 Chapman, S. D.: "British-Based Investment Groups before 1914", The Economic History Review, 1985, págs. 230-251; Charles Jones: "Great capitalists and the Direction of British Overseas Investment in the Late Nineteenth Century: the Case of Argentina, Business History, 22:2, 1980; International Business on the Nineteenth Century: The Rise and Fall of a Cosmopolitan Bourgeoisie, Brighton, 1987; y "Los antecedentes de la moderna corporación transnacional: los grupos de inversión británicos en América Latina", en Marichal, C. (coord.): Las inversiones extranjeras en América Latina, 1850-1930, México, 1995; y, sobre el período anterior, Reber, Vera Blinn: British Mercantile Houses in Buenos Aires, 1810-1880, Xerox University Microfilms, 1975.

11 Wilkins, Mira: "The free-standing company, 1870-1914: an important type of British foreign direct investment", The Economic History Review, XLI:2, 1988, págs. 259-282. Véanse las reservas que esta autora plantea sobre la autonomía de su objeto de estudio, y su discusión en Miller, Rory: "British Free Standing Companies on the West Coast of South America", 11 International Economic History Congress, Milán, 1994. 
familiares en el origen de los establecimientos de banca "privada", que configuraban, de hecho, verdaderos grupos en sí mismos. A través de ellos obtenían el grueso de los recursos, y también las conexiones necesarias para los negocios en los que se iban a emplear. En ese sentido, ¿no podría entenderse esta emergencia de grupos como parte de las nuevas formas de sociabilidad que desde las postrimerías del Antiguo Régimen venían modelando las nuevas élites económicas? ${ }^{12}$

La noción aparece también en los estudios que, desde Jean Bouvier en adelante, se han hecho sobre la formación de los modernos establecimientos por acciones. Desde cierto punto de vista podría hablarse de una permanencia y readecuación de las estructuras anteriores, bajo condiciones cambiantes que incluyen la "revolución ferroviaria" del siglo XIX. La nueva organización societaria no haría más que formalizar la participación de los distintos actores, que en los casos más importantes configuraban a su vez otros tantos grupos. Esto precedió al pasaje por los mercados "formales" de capitales, donde se obtuvieron fondos adicionales (muchas veces, la mayor parte), esta vez de un conjunto atomizado de "inversores" individuales. ${ }^{13}$

Finalmente encontramos el concepto en algunos de los mejores estudios franceses sobre la exportación de capitales. Aquí las inversiones externas aparecen articuladas en torno a grupos, que frecuentemente reunen los intereses de varias casas bancarias e incluso industriales. Tal vez la principal diferencia con el enfoque que proponemos se encuentre en el énfasis con que se atiende a la influencia de estos "grupos de intereses" en la definición de las políticas del Estado metropolitano, y en el propio curso de la economía francesa. ${ }^{14}$ En nuestro caso, nos importa ante todo el impacto de

12 Luthy, Herbert: La banque protestante en France de la révocation de l'Edit de Nantes à la Révolution, Paris, 1961-1970, 2 vols.; Bouvier, J., y H. Germain Martin: Finances et financiers de l'Ancien Régime, Paris, 1964; Levy Leboyer, Maurice: Les banques européenes et l'industrialisation internationale dans la première moitié du XIX siècle, Paris, 1964; Bergeron, Louis: Les Rothschild et les autres: la gloire des banquiers, Paris, 1990.

13 Bouvier, Jean: "Recherches sur l'histoire des méchanismes bancaires en France dans le dernier tiers du XIXe.siècle. Sources et problemes", Histoire économique et histoire sociale, Ginebra, 1968; y Landes, David: "The Old Bank and the New: the Finantial Revolution of the 19th. century", en Crouzet, F.: Essays in European Economic History 1789-1914, London, 1969, págs. 112-128. Una descripción de las redes que sostenían a estos grupos financieros en Landes, David: Bankers and Pashas. International Finance and Economic Imperialism in Egypt, London, 1958.

14 Barjot, Dominique: "La Grande Entreprise de Travaux Publics.Contraintes et Stratégies, 18831974", Université de Paris IV, 1989, tesis doctoral inédita; Broder, Albert: "Le role des intérets étrangers dans l'économie espagnole, 1768-1925", Atelier des Thèses de Lille, 1984, tesis doctoral (microfichas), vol. 8; Girault, Réné: Emprunts russes et investissements français en Russie 1887-1914, Paris, 1973; Thobie, Jacques: Intérets et impérialisme français dans l'Empire ottoman (1895-1914), Paris, 1977. 
su presencia en la economía y sociedad receptora. El estudio de estos grupos, y de su relación con los otros actores, del sector público o privado, nativos o extranjeros, en el medio en el que les tocó actuar, constituye una herramienta para hallar algunas claves explicativas de su patrón de inversiones, y de su papel de partícipes y modeladores en el proceso de transformaciones económicas y sociales en curso.

\section{Los grupos inversores franceses en la Argentina. Un ensayo de caracterización}

En la configuración de los grupos inversores franceses en la Argentina hay una característica que resalta con claridad: es la presencia dominante de las grandes firmas bancarias, que los diferencia de otros casos más heterogéneos como el de los grupos británicos. El peso decisivo que los grandes bancos franceses tenían sobre el mercado financiero de París, tornaba indispensable su participación en negocios que, en este período, solo podían financiarse en ese mercado. ${ }^{15}$

\section{La formación de los primeros grupos (1881-1890)}

Los dos primeros grupos franceses en la Argentina se formaron a comienzos de la década de 1880, a raiz de la negociación de empréstitos con el gobierno nacional: uno se constituyó en torno de la Banque de Paris et des Pays Bas (BPPB), y el otro, de la Société Générale (SG). La intervención de estos dos grandes bancos supuso una ruptura con su orientación previa, hacia Europa y el Mediterráneo, que pudo verse facilitada por la coyuntura de auge de 1879-82 del mercado de valores de Paris. Encontramos antecedentes de su interés por la Argentina desde principios de la década de 1870, así como operaciones previas de caracter similar en

15 Este tema fue tratado en el capítulo III de nuestra tesis: Regalsky, Andrés: "Marchés financiers, groupes d'investissement et élites locales: les investissements français en Argentine, 1880-1914", Université de Paris I, 1997. De la abundante literatura al respecto puede consultarse Levy-Leboyer, Maurice: "Le Crédit et le Monnaie", en Braudel, F., E. Labrousse et al.: Histoire économique et sociale de la France, III:1, Paris, 1976, págs. 347-471; Bouvier, Jean: "L'extension des réseaux de circulation de la monnaie et de l'épargne. Système bancaire et marchés de l'argent", Braudel, F. , y E. Labrousse: Histoire économique et sociale de la France, IV:1, Paris, 1977. 
otros países sudamericanos. ${ }^{16}$ La composición de los grupos se ajustó al cuadro de vinculaciones que mantenían sus integrantes en el mercado francés. El agrupamiento conducido por la BPPB, el primero en introducirse en los negocios argentinos, incluía otros dos miembros, Comptoir d'Escompte y L\&R Cahen d'Anvers. Comptoir, uno de los grandes bancos de depósitos del período, era el colaborador más asiduo de la BPPB en esta etapa en la colocación de títulos entre el gran público, a través de su amplia red de sucursales. Cahen d'Anvers, una firma privada ligada de antiguo por lazos de parentesco con algunos de los fundadores de BPPB (Bifschofsheim, Bamberger), parece haber cumplido, según lo sugieren indicios posteriores, la función de articulador inicial del grupo francés. ${ }^{17}$

Cada miembro del grupo o "sindicato" original, era cabeza de otro grupo o "subsindicato". La BPPB había sido definida en un principio como un verdadero sindicato de banqueros formalizado en sociedad por acciones. Sus miembros más conspicuos mantenían por lo menos tres instancias de participación en los beneficios de las operaciones: como accionistas, a través de los dividendos, como directores a través de los "tantièmes", y en tanto firmas asociadas (la "table") por la retrocesión del $50 \%$ de cada negocio que obtuviera el banco. ${ }^{18}$ Comptoir y Cahen también conformaban sendos grupos, el primero con los financistas que participaban en el directorio (algunos de ellos, como Pierre Girod, ligados a la Haute Banque), y el segundo con otras casas privadas, como Heine, de origen alemán, que atraía a otros participantes de esa nacionalidad.

Los tres miembros originales integraban el sindicato "contratista", ${ }^{19} \mathrm{el}$ único que asumía compromisos formales ante el gobierno. Junto a los otros participantes formaban el "sindicato de garantía", que debía tomar los títulos que no pudieran colocarse entre el público. Luego venía la emisión,

16 Ver la presentación de Société Générale ante el gobierno argentino en 1870, para la emisión de un nuevo empréstito de obras públicas, en Ministerio de Economía (Argentina), Archivo de la Deuda Pública, carpeta 2088. El comienzo de la guerra franco-prusiana impidió esta iniciativa. De la misma, ver la participación de financistas continentales en el Merchantile Bank of River Plate, a fines de 1873, en Jones, Charles: "British Financial Institutions in Argentina, 1860-1914", Cambridge, 1973 (tesis doctoral inédita), págs. 39-43. Sobre la importancia de la coyuntura de 1879-81 para la búsqueda de nuevos negocios, Bouvier, Jean: Le Crédit Lyonnais; les années de formation d'une banque de dépots: 1863-1882, Paris, 1961, 2 vols.

17 Información general en Baldy, Edmond: Les Banques d'Affaires depuis 1900, Paris, 1922. Sobre los lazos entre Cahen y el grupo fundador de la BPPB, Banque Paribas, Paribas 1872-1972, Paris, 1972, y Coston, Henry: Dictionnaire des dynasties bourgeoises et du monde des affaires, Paris, 1975.

18 Ver referencias a esta práctica en Bussiere, Eric: Paribas, 1872-1992. L'Europe et le monde, Paris, 1992, y Banque Paribas, Paribas 1872-1972... También se la puede apreciar en el cuadro adjunto.

19 Sindicat apporteur, en la terminología usada por Girault: Emprunts russes..., pág. 28. 
confiada en este caso al Comptoir y en menor medida a la BPPB. La fuente principal de utilidades estaba dada por la brecha entre el precio de emisión y el convenido con el gobierno. Es evidente que la diversa participación funcional de los banqueros implicaba niveles de "beneficios" diferenciales. Los socios contratistas recibían una comisión predeterminada sobre los títulos atribuidos a cada uno, y lo mismo sucedía con los establecimientos que se ocupaban de la emisión, en tanto que el sindicato de garantía practicaba entre sus miembros una liquidación de beneficios de orden variable, según el éxito final de la operación. ${ }^{20}$

El otro grupo, integrado por la Société Générale y el Crédit Industriel et Commercial (CIC), tuvo un perfil algo distinto. El esquema de un banco de negocios asociado con uno de depósitos, que hemos visto funcionar en el grupo anterior y que alguna bibliografía consagra como el único vigente, no se verificaba en este caso. Tampoco participaban casas privadas como la de Cahen. Los dos establecimientos del grupo correspondían al tipo de "banco de depósitos" que, se suponía, debía jugar solo un rol de colaboración o acompañamiento. Cabe recordar, sin embargo, que la SG había sido organizada en sus comienzos de acuerdo a un modelo de "banca mixta", similar al del Crédit Mobilier, que nunca había abandonado del todo. Sus primeras operaciones le habían dejado negocios de participación en diversos países, incluidos los sudamericanos, que hacia 1890 superaban, en términos absolutos, a los del principal banco de negocios, BPPB. ${ }^{21}$

Lo más notable en este grupo era la participación del CIC, distinguido en la bibliografía como el exponente más cercano al modelo británico de banca "pura" de depósitos. Carecía por entonces de una red de sucursales en provincia que pudiera tornar significativa su participación en la colocación de los títulos. En rigor, aparecía como una filial de hecho de la SG, varios de cuyos directores y representantes compartía. Este perfil menos autónomo y "comercial" del que se postula, tal vez haya influido en la crisis que soportó el establecimiento a principios de los 90, luego de lo cual habría adoptado un perfil más conforme al de la imagen histórica que perdura. ${ }^{22}$

20 Por ejemplo, la liquidación recibida por Heine por el empréstito de 1881 fue de $5.28 \%$ (Archives Nationales, Archives d'Entreprises (AN-AE), 115 AQ 14, 23 de mayo y 26 de septiembre 1881). La BPPB, en su condición de chef de file del Sindicato contratista y de su rol en la colocación, percibió 9.2\%: Archivo de la Banque Paribas (ABP), Procès-Verbaux du Conseil d'Administration, 27 de septiembre de 1881).

21 Baldy: Les Banques d'Affaires...

22 Levy-Leboyer: "Le Crédit et le Monnaie"... 
La configuración de estos grupos no quedaría completa si no se incorpora una pieza esencial para su funcionamiento: los agentes o intermediarios en Buenos Aires. Su participación era indispensable en las negociaciones previas con los gobiernos, que determinaban las condiciones y donde se jugaba la posibilidad misma de obtener el negocio. La presencia de estos intermediarios se generalizó a partir de la instalación del cable telegráfico con Europa, en 1876, que modificó las técnicas de negociación vigentes. Hasta ese momento, los gobiernos recurrían al envío de un comisionado con plenos poderes a Europa, que negociaba directamente con las diversas casas bancarias de acuerdo a las bases mínimas que se le habían estipulado (y a veces, apartándose ostensiblemente de ellas). ${ }^{23}$

Las operaciones con los grupos franceses a comienzos de la década de 1880 fueron las primeras que incluyeron la negociación en Buenos Aires a través de representantes locales de las casas europeas. Una parte de la tramitación continuó realizándose en Europa: la formalización del contrato definitivo o "General Bond", con la participación de un representante (generalmente diplomático) del gobierno. A veces constituyó la oportunidad para introducir modificaciones nada formales en las condiciones, como sucedió con el contrato definitivo del empréstito de Obras de Salubridad y Puerto del Riachuelo, firmado en 1883 por el ministro argentino en París. ${ }^{24}$ En dos oportunidades, en 1885 y 1890, la complejidad de las negociaciones y la multiplicidad de los interlocutores llevaron al gobierno a retornar al sistema de un comisionado especial que tratara en Europa con los banqueros. Pero se trató de la renegociación global de varios empréstitos, y por otra parte sus resultados, poco satisfactorios para los intereses del gobierno argentino, indujeron a no repetir la experiencia. ${ }^{25}$

23 Ver la correspondencia de los ministros de hacienda con los comisionados, De la Riestra et Varela, a propósito de la negociación en Londres de los empréstitos de 1866-68 y 1871, respectivamente, en Ministerio de Hacienda (Argentina), Memoria, Buenos Aires (1868), anexo B, y Ministerio de Economía (Argentina), Archivo de la Deuda Pública, carpeta 2094 (febrero-junio de 1871).

24 En ese contrato se suprimió la mención de un plazo determinado para llevar a cabo la emisión de los títulos, hecho que debilitó la posición del gobierno más adelante. El ministro, Balcarce, había recibido una participación en el sindicato de garantía al que se habían retrocedido éste y anteriores empréstitos: Archives de la Banque Paribas (ABP), Dossiers divers, 252-4: "Lettres à Morton Rose" (13 y 18 de noviembre de 1882) y 252-2A/5H: "Tableau Général des Participants".

25 En 1885 fue enviado Pellegrini, siguiendo instrucciones del presidente Roca, pero pronto entró en conflicto con el ministro de Hacienda debido a las condiciones del contrato que firmó. Ministerio de Economía (Argentina), Archivo de la Deuda Pública, carpeta 2096, telegramas intercambiados (abril-junio de 1885). En 1890 fue enviado Victorino de la Plaza a negociar con Baring, antes de la caída de esta casa bancaria. Sus acuerdos con Rothschild debieron ser luego modificados. Ministerio del Interior (Argentina), Archivo General de la Nación (AGN), Archivo de Victorino de la Plaza, SalA 7, 5-5-13 y 6-2-12/13 (correspondencia, 1880-1909). 
La representación de los grupos franceses fue asumida por casas pertenecientes al "alto comercio" (como gustaba denominarse, a la francesa) de Buenos Aires. Estas firmas, ligadas por razones de su giro comercial con la plaza de Paris, venían orientandose crecientemente hacia los negocios financieros. De modo similar a lo sucedido con los merchant banks, a partir de la revolución de las comunicaciones que impuso el telégrafo y la navegación a vapor, estas firmas se encontraron con cuantiosos fondos disponibles, por los menores requisitos de stock, que destinaron a operaciones de crédito y negocios de todo tipo. La entrada de nuevos actores, que puso en cuestión su posición predominante en el campo comercial, también contribuyó a ese viraje en favor de los negocios financieros. Las antiguas relaciones de crédito que mantenían con las grandes casas comerciales y bancarias europeas, pudieron ser el punto de partida de su integración en los grupos inversores de los que estamos hablando. ${ }^{26}$

Los agentes locales que colaboraron con los dos grupos examinados fueron Bemberg, Heimendahl y Compañía (con el grupo de la BPPB), y Franz Mallmann y Compañía (con el de la SG). Estas antiguas casas comerciales, progresivamente volcadas a las operaciones financieras, disponían de una estructura apropiada para cumplir este papel, por su doble base en Buenos Aires, cerca de las fuentes de los negocios, y en Paris, en contacto directo con los banqueros. El propio fundador de la casa Bemberg, Pedro Otto, se había instalado en París en 1880, dejando en Buenos Aires a su socio Rudolph Heimendahl, secundado por su hijo Otto Sebastián. Por su parte Franz, y luego Emile de Mallmann, operaban simultaneamente entre Buenos Aires, Montevideo y Paris. ${ }^{27}$ Ambas casas, a la vez que rivales, conservaron cierta afinidad, puesta de manifiesto en la similitud de sus vinculaciones europeas, que dio lugar a importantes negocios comunes, como en la participación de Heimendahl primero con Bemberg, luego con Mallmann (fines de la década de 1880) y, tras la bancarrota de éste en los años 90, nuevamente con su socio inicial. ${ }^{28}$ La sólida posición de estos personajes en el seno de la élite local y entre los círculos financieros de París,

26 Jones: "British Financial Institutions..., págs. 62-67.

27 La relación de Mallmann con la Société Générale era reciente. Este banco disponía al menos desde 1870 de un agente regular en Buenos Aires, Blacque, Vignal y Compañía, una caracterizada firma de la colonia comercial francesa. A través de ella formuló sin éxito sus primeras propuestas, en 1870 y en 1880. Ministerio de Economía (Argentina), Archivo de la Deuda Pública, carpeta 2088.

28 A tal punto, que la presencia de Mallmann junto a la SG en 1884 hizo pensar asimismo en una participación encubierta del "petit Cahen", perteneciente formalmente al primer grupo. Hoskier a Sautter, 17 de marzo de 1884, en Archives de la Banque Paribas (ABP), Dossiers divers, carton 250:17. 
se veía reforzada en algunos casos por oportunos enlaces: de Bemberg y Heimendahl con las Ocampo, y de una hija de Pedro Otto con el vástago del banquero Jacques Stern. Este último, integrante de la conducción de la $\mathrm{BPPB}$, tomaría una participación especial en todas las operaciones argentinas del grupo en estos primeros años (ver cuadro 1). ${ }^{29}$

Tal vez el exponente más destacado de esta estrategia de vinculaciones sea Ernesto Tornquist. Su compañía apareció en este período vinculada al alto comercio de Amberes, y a destacados intereses industriales y financieros de Alemania (Krupp, Disconto Gesselschaft), patria de origen de varios ancestros de la firma (Bunge, Bornefeld, Altgelt y los mismos Tornquist), mientras que en el ámbito local, además de las vinculaciones familiares con la élite por el costado materno, varios de los abogados de la firma ocuparían el Ministerio de Hacienda de la Nación (J.J.Romero, E.Berduc, J.M.Rosa) y el propio Ernesto Tornquist desempeñaría, en sus últimos años, el cargo de senador. La empresa, responsable de la introducción de los bancos alemanes en las operaciones con el gobierno argentino a mediados de los años 80 , se reubicaría una década más tarde como representante de los grupos británicos hegemónicos, y también de ciertos grupos franceses en la esfera de los negocios hipotecarios. ${ }^{30}$ Sin alcanzar el mismo relieve, las casas antes mencionadas ejercieron una significativa influencia en el medio local en la década de 1880, reflejada en la participación de Mallmann y de Heimendahl en el directorio del semi-oficial Banco Nacional, y en los contactos de Bemberg y Heimendahl con la flamante administración del presidente Roca en 1880, que permitieron al grupo de la BPPB la obtención de su primer empréstito argentino.

Otro aspecto significativo en el funcionamiento de estos grupos franceses, fue la estrecha colaboración que mantuvieron con casas bancarias británicas, a las que confiaron la emisión de una parte o de la totalidad de los títulos. Al principio influyó la inseguridad de poder colocar los títulos argentinos en un mercado hasta entonces ajeno a esta clase de valores. Así

29 Véanse los lazos de parentesco en Ministerio del Interior (Argentina), Archivo General de la Nación, Sucesiones, 4247: Pedro Otto Bemberg (1895), y en Cutolo, Vicente: Nuevo Diccionario Biográfico Argentino, Buenos Aires, 1968.

30 Ver la abundante bibliografía publicada por la misma empresa: Tilmant, Jean: Ernesto Tornquist et Compagnie et le commerce anversoise, Amberes, 1908; Tornquist, Ernesto, y Compañía: Crónica de la casa, Buenos Aires, 1922; Tornquist, Ernesto, y Compañía: Antecedentes de Ernesto Tornquist y Compañía y de sus compañías afiliadas, Buenos Aires, 1932; Institución Tornquist, Ernesto Tornquist, 1842-1942, Buenos Aires, 1942, y más recientemente, los estudios de Sabato, Jorge Federico: La clase dominante en la Argentina moderna. Formación y características, Buenos Aires, 1988. 
pues, el grupo de BPPB decidió operar con la angloespañola Cristóbal de Murrieta, que había efectuado en Londres la última emisión de títulos argentinos. A partir de 1882, la crisis redujo a un mínimo la receptividad del mercado de Paris, y entonces la asociación con las firmas británicas implicó asegurar el acceso a la única plaza donde todavía había una demanda significativa de estos valores. Tras asociarse en 1882-83 con la firma angloamericana de Morton Rose, el grupo de BPPB debió recurrir al partenaire más poderoso, Baring Brothers, hasta entonces su principal adversario, mientras el grupo de la Société Générale, hizo lo propio con otra importante casa británica, J.S.Morgan. ${ }^{31}$

La segunda mitad de los año 80 asistió a una diversificación de los grupos franceses, como así también, a importantes cambios en su composición. Por una parte, su participación en los empréstitos públicos nacionales se redujo a un mínimo y tornóse más pasiva. El conjunto de los bancos analizados intervino como sección francesa de un consorcio internacional encabezado alternativamente por las grandes firmas británicas y alemanas, en dos empréstitos de conversión cuyos títulos, significativamente, no se colocaron en París. Al mismo tiempo, nuevos rubros atrajeron el grueso de los capitales: empréstitos provinciales, compañías de crédito hipotecario y ferroviarias. Estas últimas constituirían las primeras inversiones "directas" de este origen.

El primitivo grupo de la BPPB se fraccionó en dos segmentos. Por una parte, Cahen d'Anvers se constituyó en el eje de un agrupamiento de dimensiones variables, en asociación con Heine, y a veces Comptoir, que tomó diversos empréstitos provinciales. En menor medida también actuó en esta esfera el grupo de SG. La gestión local estuvo a cargo de Bemberg y, en un caso, de Mallmann. La primera firma (ahora conducida directamente por el hijo del fundador, Otto Sebastián), tuvo en estos años un amplio campo de acción. Por una parte, intervino en cinco de los seis empréstitos en cuestión, incluído el de Mendoza, en cuya negociación se interesó el propio general Roca. ${ }^{32}$ También colaboró en las operaciones de crédito de un conjunto de bancos franceses y alemanes con el Banco

31 Archives de la Banque Paribas (ABP), Dossiers divers, 252-4/5c, correspondencia con Morton Rose (noviembre de 1882), y 250-17, correspondencia con Hoskier (marzo-abril de 1884). Sobre Morgan, ver también Burk, Kathleen: Per Ardua ad Astra. Morgan Grenfell 1838-1988, Oxford University Press, 1989, pág. 47.

32 Mateu, Ana María: "Bancos, créditos y desarrollo vitivinícola", Cuadernos de Historia Regional, 17/18, Universidad Nacional de Luján, 1995. 
Nacional. Por otra parte, obtuvo concesiones ferroviarias (una de las cuales, de Córdoba al Noroeste, colocó en el mercado británico), y es posible que haya acompañado a Cahen en la fuerte participación que esta casa tomó en otra compañía, el Ferrocarril Nordeste Argentino, con sede en Londres. ${ }^{33}$ Mallmann tuvo una intervención mucho más modesta como agente de la SG. También representó al mencionado consorcio francoalemán en algunas operaciones con el Banco Nacional y con la municipalidad de Buenos Aires. ${ }^{34}$

La BPPB, ahora distanciada de Bemberg, se interesó en un nuevo agrupamiento que tomó a su cargo las primeras inversiones en sociedades anónimas, localizadas en la provincia de Santa Fe. El elemento más activo parece haber sido un conjunto de financistas aglutinados en la Banque Russe et Française (BRF), la Société Française des Etudes et Entreprises (SFEE) y la Compagnie des Constructions Mechaniques de Fives Lille. Esta última compañía, de destacada trayectoria en la construcción de ferrocarriles en el continente europeo, debió lanzarse a la búsqueda de nuevas operaciones en ultramar por la declinación de sus mercados tradicionales. Dada la presencia de los elementos financieros, se orientó hacia la participación en sociedades cuyo equipamiento pudiera controlar. ${ }^{35} \mathrm{Su}$ implantación en la Argentina, donde creó dos compañías ferroviarias, se vio favorecida por los vínculos comerciales que ya mantenía en el país, como principal proveedor de maquinaria azucarera. El epicentro de su nuevo accionar estuvo en Santa Fe, donde pocos meses antes algunos de sus asociados habían colaborado en el lanzamiento de una compañía de créditos hipotecarios cuyos recursos se iban a obtener en el mercado de París. La participación de BPPB, ausente en esta primera operación, resultó indispensable para la concreción de los proyectos ferroviarios.

En estos negocios se advierte particularmente el papel decisivo de los intermediarios locales. En un caso, el del banco hipotecario, de un personaje de la política local, Llambí Campbell, que había dirigido previamente la famosa entidad homóloga de la provincia de Buenos Aires. En el otro, de

33 The Statist, Londres, 1888, pág. 277. Véase también Cassis, Youssef: La City de Londres 1870-1914, París, 1987, pág. 159, y Archivo de la Banque Paribas (ABP), Procès-Verbaux du Conseil d'Administration, 24 de mayo y 7 de junio de 1888.

34 Archives Nationales, Archives d'Entreprises (AN-AE), 115 AQ 14, 11/2: "Affaire Ville de BsAires" y 2/3: "Avances Banque Nationale", en "Syndicat 1890".

35 Sobre la intervención de los miembros financieros en la nueva orientación hacia los negocios "combinados", ver, Archives de la Compagnie de Fives Lille (AFL), Procès-Verbaux du Conseil d'Administration, 12 de marzo de 1885. 
una firma franco-argentina, Portalis y Compañía, que adquiría con el tiempo una importancia equivalente a Tornquist y Bemberg en la plaza local. Al igual que estas últimas, aunque con una implantación más reciente, desplegaba sus actividades financieras junto a las de exportación e importación, y había obtenido unos años antes la representación de Fives Lille en la Argentina (excepto Tucumán). ${ }^{36}$

\section{La crisis de 1890: reorganización y nuevos avances}

La crisis de 1890 marcó una interrupción en el flujo de las inversiones, y abrió paso asimismo a una profunda reorganización en el seno de los grupos establecidos. En las sociedades auspiciadas por BRF y Fives Lille, la BPPB pasó a asumir un rol más importante. La limitada capacidad financiera de los dos socios iniciadores, que desembocó en la quiebra de la BRF y la salida de Fives Lille del negocio ferroviario, fue su contrapartida. El espacio ganado no implicó que la BPPB asumiera la conducción directa, sino sólo un poder de veto. En el rubro hipotecario, un grupo local asociado al promotor tardaría años en ser desplazado. En la compañía ferroviaria de Santa Fe, la presidencia quedaría en manos de uno de sus antiguos aliados (Ewald) por espacio de un cuarto de siglo.

La crisis también produjo estragos entre los representantes locales. La firma de Portalis, que contaba con una comandita de Fives Lille y de la $\mathrm{BRF}$, fue disuelta tras un agrio enfrentamiento con sus socios europeos, aunque se reorganizaría rápidamente con nuevos apoyos externos. La de Mallmann se declaró en quiebra en 1894, como consecuencia de sus intentos frustrados de seguir en la línea previa (la negociación de empréstitos públicos). Ello acarreó su sustitución por Bemberg en los negocios financieros que representaba, y por las casas de Staudt y Bracht en el plano comercial. En mejor posición quedó en cambio Bemberg, que consolidaría en estos años sus intereses industriales, transformando la cervecería Quilmes, que fundara poco antes junto a su pariente Wendelstadt, en la más

36 La equiparación con Bemberg y Tornquist, en Guy, Donna: Argentine Sugar and Politics: Tucuman and the Generation of Eighty, Arizona State University, 1980, cap. III, págs. 97-106. Los hermanos Portalis, llegados de Francia en 1870, descendían de un famoso jurisconsulto y miembro del parlamento de la monarquía de Julio. Archivo General de la Nación, Sucesiones, 7615: Jules Portalis (1889). Véase también Hombres del Día, Buenos Aires, 1917, y Vedoya, Juan Carlos: "Quebracho, yerba y política", en Todo Es Historia 99, Buenos Aires, 1975, págs. 59-78. 
importante del país. Mantuvo su posición de agente local en la renegociación de los empréstitos provinciales, e intentó una iniciativa similar respecto de las cédulas hipotecarias de Buenos Aires. ${ }^{37}$

La representación local en el caso de los ferrocarriles de Santa Fe, primeramente atribuida a un ingeniero designado por Fives Lille, fue encomendada, a partir de 1893 y a instancias de la BPPB, al empresario Casimir de Bruyn. Este personaje, llegado hacía pocos años de Amberes, se había desempeñado en el comercio de exportación de lanas con una de las casas francesas más poderosas, Wattinne Bossut et Cie. Desde esa posición también obtuvo, en compañía del ingeniero Rómulo Otamendi, la representación del grupo de la BPPB. ${ }^{38}$

Durante la década del 90, De Bruyn y Otamendi se vincularon con otra serie de intereses franceses y belgas, que confluirían al cabo de unos años, en la conformación de un nuevo grupo inversor, el de la Banque de l'Union Parisienne (BUP). Se trataba, por una parte, de los empresarios Ernest Bunge y Georges Born, también llegados de Amberes,que pronto adquirieron una posición preponderante en el comercio de exportación de cereales. Hacia 1896, junto a De Bruyn, se incorporaron al comité local de un banco británico, el Anglo Argentine Bank. En dicho banco tenía una fuerte participación Edouard Bunge, el asociado de Bunge y Born en Amberes. El grupo lograría poco después incorporar a la Société Générale Belge (SGB), y en 1898 formalizarían la creación de una compañía de créditos hipotecarios en la Argentina. De Bruyn y Otamendi asumirían a partir de entonces la representación simultánea de dos grupos, pues continuarían ejerciendo la de la BPPB.

La Banque de l'Union Parisienne, fundada en 1904 para agrupar, según la versión tradicional consagrada en la bibliografía, a las antiguas casas de la alta banca protestante de París, ${ }^{39}$ incluyó como su fuerza más dinámica e influyente a la SGB. No solo su participación accionarial superaba ampliamente la de cualquiera de las otras casas, sino que estas últimas, con una trayectoria que se remontaba al menos a tres o cuatro generaciones, se hallaban ya en la etapa en que su papel pasaba más por administrar

37 The Review of the River Plate, Buenos Aires (1894), passim; Sommi, Luis: Los capitales alemanes en la Argentina. Historia de su expansión, Buenos Aires, 1945.

38 Delpech, Emile: Una vida en la gran Argentina, Buenos Aires, 1944, y Ministère de l'Economie et des Finances, Archives Economiques et Financières (MEF-AEF), B31.329, Julliemier al ministro de Asuntos Exteriores, 31 de mayo y 20 de noviembre de 1916.

39 Kaufmann, Eugène: La banque en France. Considerée principalement au point de vue des trois grandes banques de dépots, Paris, 1914; Baldy: Les Banques d'Affaires... 
el patrimonio adquirido, que por una labor creadora de nuevos negocios. La aparición del grupo de la BUP fue sin duda el hecho más significativo en el segundo ciclo de inversiones, en el cual se asistió a una multiplicación y entrelazamiento de los grupos inversores. Su representación local, a cargo de De Bruyn y Otamendi, era compartida con la BPPB. Su primer presidente, Lucien Villars, había sido previamente subdirector de dicho banco, y por tal motivo formaba parte de la dirección de los ferrocarriles de Santa $\mathrm{Fe}$, que no abandonaría en todo el período. Con una larga trayectoria en España, había viajado a la Argentina después de la crisis de 1890 para contribuir a reorganizar la compañía, y a él se atribuye la propuesta de De Bruyn como el nuevo representante. ${ }^{40}$

La expansión de los intereses franceses en la Argentina a partir de 1900 fue notable, y este fenómeno ha tendido a ser asociado con el fuerte crecimiento de los "banques d'affaires" en el mismo período, que hemos estudiado en la sección anterior. No obtante, no hubo una correlación tan exacta, como se ha querido ver, entre los nuevos "banques d'affaires" y los nuevos grupos de inversión. De hecho, otro tipo de entidades, algunas no financieras, tuvieron un papel nada desdeñable en este proceso. ${ }^{41}$

El grupo de la BPPB continuó, por cierto, siendo el más importante, tanto por los intereses que agrupaba como por los negocios en los que participó. Su fisonomía mantuvo una cierta continuidad con el ciclo anterior, y siguió sustentado primordialmente en torno a los ferrocarriles de Santa Fe. En los empréstitos públicos nacionales participó, junto a los grandes bancos de depósitos, en un consorcio internacional integrado también por los grandes bancos británicos y alemanes, y al que se agregaron en los bancos americanos. ${ }^{42}$ La colaboración con la SG, y con Baring sería uno de los pilares de la política de la BPPB a principios de siglo. ${ }^{43}$ En el caso de la SG, las relaciones habían asumido un caracter más permanente desde 1905, y a partir de entonces, este banco participaría en los ferrocarriles de Santa Fe y en los otros negocios ferroviarios montados en esta etapa. El grupo operó

40 Sobre la BUP, ver especialment Bussiere, Eric: Les relations entre la France et la Belgique 1918-1945 (Tesis doctoral inédita), Université de Paris IV, 1988; Sobre Villars, Archives de la Banque Paribas (ABP), Dossiers personales; Propuesta de De Bruyn, Dossiers divers, carton 273, ProcèsVerbaux Syndicat d'Obligataires FSF, 16 de noviembre de 1893.

41 Esta correlación, tal como surge de Baldy, ha sido aplicada al caso argentino por Marichal, Carlos: "Los ferrocarriles franceses en la Argentina", Todo es Historia 105, Buenos Aires, 1976.

42 Sobre la participación en este Consortium, las primeras referencias en Archivo de la Banque Paribas (ABP), Procès-Verbaux du Conseil d'Administration, 11 de abril de 1901.

43 Las relaciones con Baring, y la amistad Noetzlin-Cassel, son destacadas en Bussiere: Paribas..., págs. 46-47. 
también junto a Tornquist en una compañía de créditos hipotecarios que tuvo el liderazgo del mercado.

El entrelazamiento de los grupos, o cuando menos la comunidad de intereses, fue particularmente visible en el campo ferroviario. Allí el grupo de la BUP protagonizó uno de los proyectos más ambiciosos, el de una red de trocha angosta que cubriría toda la provincia de Buenos Aires. Desde un principio contó con la colaboración de la BPPB y la SG, a cambio de una representación en el directorio. Al cabo de unos años, la SG pasó a tener una actuación preponderante, por su papel en la colocación de las obligaciones, mientras que la presencia de BPPB tendió a apagarse. Lo mismo sucedió con el ferrocarril de Rosario a Puerto Belgrano, tal vez el proyecto más audaz en competencia con las grandes compañías británicas. Su implementación requirió la constelación más abigarrada de inversores franceses en una sociedad anónima. Si bien la BUP no participó, lo hicieron la BPPB, SG, Bénard \& Jarislowsky, Dreyfuss, Bemberg, Hersent y Batignolles. El papel principal fue ejercido al principio por Bénard, como presidente de la nueva compañía y coordinador del grupo metropolitano. Este pequeño pero activo banco privado, asociado con Hersent en el proyecto del puerto de Rosario, mantenía una política que lo acercaba al tipo ideal de "banque d'affaire". Su red de relaciones con Bemberg, Portalis, Dreyfuss y la BPPB le permitiría participar en diversos empréstitos provinciales. Hacia el final del ciclo sería desplazado de la conducción del grupo ferroviario por la SG y la BPPB. ${ }^{44}$

La colaboración o "entente cordiale" entre BPPB y BUP sufriría varias fisuras, que se harían primero evidentes en la esfera de los empréstitos públicos nacionales. El fracaso de la BUP en ser admitido en el consorcio internacional de Baring y la BPPB, lo llevó a competir abiertamente. En 1911, tras una serie de empréstitos tomados por ese agrupamiento, la BUP logró desplazarlo en lo que fue el importante empréstito nacional. $\mathrm{Al}$ año siguiente la colaboración que los dos bancos franceses mantenían en el plano ferroviario, a través de las compañías de Santa Fe y de Buenos Aires, sufrió un rudo golpe al integrarse el grupo de la BPPB en un holding multinacional, el Argentine Railway Company (ARC), junto a varias com-

44 Antecedentes de Bénard en Kurgan-van-Hentenryk, Ginette: "Finance and financiers in Belgium, 1880-1940", en Cassis: La City de Londres..., págs. 317-336, y "La puissance financière française vue par les milieux d'affaires belges", en Milza, P., et R.Poidevin: La puissance française à la "Belle Epoque". Mythe ou réalité?, Paris, 1992. Sobre la conducción del Ferrocarril a Puerto Belgrano, Archives Nationales, Archives d'Entreprises (AN-AE), 103 AQ 412-413, y Archives de la Banque Paribas (ABP), c.261:84, 7. 
pañías británicas. Esta decisión, en la que parece haber tenido incidencia la SG, consagró una separación más definida de intereses entre ambos grupos, y desde entonces De Bruyn y Otamendi quedaron solamente con la representación de la BUP.

Un grupo nuevo, con un perfil bien distinto a los anteriores, se constituyó en el segundo ciclo alrededor del puerto de Rosario. En éste los intereses dominantes no fueron bancarios o financieros, sino básicamente "industriales". Se trataba del consorcio formado por las empresas Hersent y Schneider para la construcción y explotación de dicho puerto. El grupo contó con el apoyo de varias casas bancarias, como el CIC, pero con funciones bien acotadas. Bénard, el verdadero banquero del consorcio, se ocupó de la "ingeniería financiera", mientras que la constructora Hersent fue la que realmente tomó a su cargo la gestión del negocio. Parte del interés de esta firma iba a ser posteriormente reciclar su estructura en obras nuevas, y con ese objeto el grupo ensayó otras participaciones. En vísperas de la negociación de un nuevo empréstito argentino, el grupo intentó asegurarse pedidos en varios proyectos del gobierno nacional, en una serie de episodios que generaron fricciones diplomáticas de cierta entidad..$^{45}$ Con el mismo fin el grupo Hersent aceptó incorporarse al Ferrocarril de Rosario a Puerto Belgrano, y tomó a su cargo la construcción de los muelles que la compañía iba a explotar en ese puerto terminal. Además al grupo le interesaba el tráfico adicional que brindaría al puerto de Rosario ese ferrocarril. De hecho, el mayor nivel de actividad de esta línea se logró, precisamente, en el tramo orientado hacia este puerto.

Otros grupos menores y de estructura más inestable quedaron conformados alrededor de los empréstitos. Encontramos frecuentemente asociados a los ya citados Bénard y CM, así como a Dreyfuss y un establecimiento argentino, el Banco Español del Río de la Plata (BERP). Este último, un banco formado por la élite mercantil española de Buenos Aires, colocaba los títulos obtenidos a través de su sucursal en Paris. Por su parte

45 El estudio más importante sobre el grupo Hersent es el de Barjot: "La Grande Entreprise de Travaux Publics...". Sobre Schneider, véase d'Angio, Agnès: "La politique de Travaux Publics de Schneider et Compagnie de 1895 á 1910” (memoria de maestría), Universidad de París IV, 1992. Para el negocio del puerto de Rosario ver los fondos depositados en Archives Nationales, Archives d'Entreprises (AN-AE), 211 AQ 1-5: Société Financière de Rosario, y el capítulo VI de nuestra tesis. Con respecto a las fricciones diplomáticas, véase la correspondencia entre los ministros franceses de Finanzas y de Asuntos Extranjeros en Ministère de l'Economie et des Finances, Archives Economiques et Financières (MEF-AEF), B31.326 (año 1908). Ver también el capítulo VIII de nuestra tesis doctoral: "Marchés financiers...". 
Dreyfuss, la principal exportadora de granos de la Argentina y tal vez del mundo, desarrollaba sus operaciones financieras con aparente autonomía, asimilable a un banco privado. En ese caracter intervino en uno de los ferrocarriles, donde convergían sus intereses financieros más los del tráfico de granos que se suponía iba a generar. ${ }^{46}$

En estos grupos continuaron desempeñando un papel importante los elementos locales, algunos de ellos caracterizados miembros de la élite local. En el Ferrocarril de Rosario a Puerto Belgrano intervino como concesionario inicial Diego de Alvear, gran propietario rural y una de las personalidades de la época, y luego Bemberg, que se ocupó de reunir a los diversas firmas europeas que conformaron el agrupamiento definitivo. En este negocio se puso en juego, asimismo, la participación de personajes de la élite local. El ingeniero Bustos Morón, también fuerte propietario de tierras, que como subsecretario de Obras Públicas de la Nación intervino en la aprobación de los presupuestos y materiales del puerto del Rosario, tuvo una peculiar relación con el grupo contratista y luego, al constituirse el Ferrocarril a Puerto Belgrano, fue designado al frente del comité local en Argentina.

Por lo que queda dicho, en este ciclo actuaron algunos de los intermediarios locales que lo habían hecho en el ciclo anterior. Otto Bemberg, antes y después de intervenir en este agrupamiento antes citado, tuvo un papel aún más destacado en otro negocio ferroviario de la provincia de Buenos Aires, la construcción de una línea para el estado provincial. Su relación con el gobierno bonaerense databa de sus gestiones para el arreglo de las cédulas hipotecarias. Otro de los que reaparecieron fue Portalis, que operó como agente local en dos importantes empréstitos de las provincias de Buenos Aires y Santa Fe contratados en 1910 por BPPB, aunque no como asociado de ese banco sino del otro miembro contratista, Bénard, con el que anudó una amistad personal. También participó junto al Crédit Mobilier en otros dos empréstitos de Buenos Aires, y junto al Banco Francés del Río de la Plata, entidad de la colonia local, en un empréstito de Corrientes. En ambos casos se trató de emisiones conjuntas con un "merchant banker" británico, Erlanger \& Co., con el que Portalis se había ligado estrechamente. Con su apoyo, Portalis había participado en nuevas áreas de inversión: la de los ingenios azucareros, en sociedad con

46 Sobre el Banco Español, Fernández, J. A.: La banca argentina, su actuación y desarrollo, Buenos Aires, 1912. Sobre Dreyfuss, Morgan, Dan: Los traficantes de granos, Buenos Aires, 1982. 
el empresario francés Hileret, y la de las explotaciones forestales de Santa Fe y el Chaco, donde constribuyó a constituir a principios del siglo el "trust" La Forestal. ${ }^{47}$

En los años previos a la Primera Guerra Mundial Portalis acompañó a Erlanger en el lanzamiento de varias empresas argentinas en el mercado británico (Argentine Tobacco, Gath y Chaves). Tambien participó junto a otros financieros locales (Bemberg y Tornquist) en la reorganización de una gran empresa industrial (Cristalerías Rigolleau). Hacia el final del ciclo, la propia firma de Portalis fue reorganizada como sociedad anónima, y así se consolidaron las participaciones de sus socios locales y europeos: Bénard, Erlanger, Bracht, étc. Uno de los nuevos intermediarios financiero de este período fue Theodore Bracht y Cía, firma argentino-belga de origen alemán. Operaba desde hacía mucho en la plaza, en el rubro de la exportación de lanas al mercado de Amberes. Además de sus vinculaciones con Portalis, que implicaron la participación en varias inversiones conjuntas (sobre todo compañías de tierras) también se vinculó por alianzas matrimoniales con Bunge y Born, hacia el final de este ciclo. En el empréstito nacional de 1911 actuó junto a De Bruyn en la representación del consortium tomador, probablemente por los intereses belgas que acompañaron a la BUP. ${ }^{48}$

\section{Conclusiones}

La evolución de los grupos franceses y del cuadro de sus intereses en la Argentina, tal como ha sido delineada en este capítulo, sugiere algunas observaciones finales que consideramos importante destacar. En primer lugar, la existencia de un sesgo diferencial con respecto a los grupos de origen británico, por el papel más destacado de las entidades bancarias. Este rasgo se ha podido relacionar con las diferencias observadas en los respec-

47 Gori, Gastón: La Forestal. La tragedia del quebracho colorado, Buenos Aires, 1965; Cowen, Michael: "Capital, nation and commodities: the case of Forestal Land Timber an Railway Company in Argentina and Africa 1900-1945", Van Helten, J.J., y Y.Cassis: Capitalism in a Mature Economy, Worcester, 1993, págs. 186-216.

48 Sobre los negocios de Bracht y Portalis en la Argentina, Monitor de Sociedades Anónimas, Buenos Aires (1905-1914); sobre su alianza con Bunge y Born, Green, Raúl, y Catherine Laurent: El poder de Bunge \& Born, Buenos Aires, 1989. Para el empréstito de 1911, ver Cámara Francesa de Comercio, Boletín, Buenos Aires, junio de 1911, y Ministerio de Hacienda (Argentina), Memoria, Buenos Aires, (1911-I), pág. LXXXII. 
tivos mercados financieros, que en el caso francés se reflejaban en su caracter marcadamente centralizado en torno a los grandes bancos. La presencia de dichas entidades, excluyente en los primeros grupos, por la propia naturaleza de sus operaciones (los empréstitos argentinos de comienzos de la década de 1880), continuó siendo dominante cuando a fines de la década se plantearon otro tipo de negocios, los ferroviarios.

En los grupos que operaron en negocios ferroviarios, y posteriormente portuarios, se ha podido observar, asimismo, el papel nada desdeñable de empresas industriales y de obras públicas, algo que tampoco era habitual en los grupos de origen británico. Pero en estos casos, como en los anteriores, es perceptible una lógica que no pasaba necesariamente por la rentabilidad intrínseca los negocios, sino que parece más bien haberlos trascendido, y que se puede vincular con las ventajas "externas" que los mismos debían proporcionar.

En lo que concierne a las empresas industriales y de obras públicas, su participación les iba a permitir obtener un mercado "cautivo" o bajo condiciones especiales, con una rentabilidad sin duda diferencial con respecto a la que les dejaban sus operaciones ordinarias. Lo mismo puede decirse del otro tipo de actores. Para los bancos, los negocios no estaban planteados en función de la rentabilidad de los fondos en ellos invertidos, sino de la que les iba a procurar su posición de proveedores de ciertos "servicios" financieros. En todos los casos, los fondos debían provenir principalmente del público ahorrista y no de los miembros del grupo inversor. Entonces lo que más interesaba era la posibilidad de colocar los títulos en condiciones tales de asegurar una comisión elevada para sus emisores y, si la empresa tenía éxito, captar otra porción de beneficios en su condición de accionistas.

Este tipo de intervención parece descartar "a priori" cualquier tipo de interés sobre el contenido del negocio que hiciera pensar en una estrategia de inversión derivada del mismo. No creemos que haya que ir tan lejos. La elección del contenido no estaba totalmente librada al azar, ni dejada a la exclusiva voluntad de los actores. Por una parte, se hallaba acotada a aquellos rubros que los mercados metropolitanos estaban dispuestos a aceptar, en países y en rubros capaces de alimentar expectativas favorables del público. Pero sobre todo la elección del contenido estaba acotada por las condiciones locales: aquello que era viable en la Argentina, y que podía generar una rentabilidad suficientemente atractiva como para sostener la intervención de los grupos inversores: no, por ejemplo, en las explotaciones rurales, donde los empresarios nativos se desenvolvían con una solven- 
cia y un conocimiento de la situación que los tornaba imbatibles, sino allí donde ese capital local era insuficiente o incapaz de concurrir, sin el respaldo de un mercado de ahorradores como el europeo. Tales condiciones eran especialmente propicias en el sector de obras de infraestructura (ferrocarriles, puertos), y en los mercados del dinero: de ahí su participación en la creación de establecimientos de crédito (hipotecas, comercio exterior) y en la provisión de fondos para un tomador insaciable en el escenario local: el Estado.

La secuencia recorrida por los grupos inversores en su implantación específica en los diferentes negocios, así como la configuración de intereses que fueron adquiriendo, dependió sobre todo de las oportunidades emanadas de una bullente realidad local, donde interactuaban las necesidades del crecimiento económico, las políticas implementadas desde el Estado en el nivel nacional y provincial, y el propio juego entre los intereses locales y los otros grupos extranjeros ya establecidos. Este último aspecto, de notable significación en un proceso en el que los capitales franceses no eran ciertamente los primeros en llegar, se puede correlacionar con el importante papel que en la gestación de las inversiones tuvieron los intermediarios y agentes locales. La presencia de estos elementos, por las estrechas vinculaciones que permiten adscribirlos a las élites, y el propio peso que adquirieron en el medio financiero local, se diferencia notoriamente de lo observado en el caso de las inversiones británicas. Su importancia no cedería aún en el segundo ciclo de inversiones, dándoles a estos grupos ese matiz tan particular, que resultó funcional para los proyectos de diversificación de las fuentes externas de financiación por parte de las élites locales, en un momento en que sus relaciones con los grupos británicos distaban de ser armoniosas. 


\section{Cuadro 3}

CUADRO GENERAL DE PARTICIPACIONES EN EL EMPRÉSTITO

BILLETES DE TESORERÍA (1882), EN MILES DE LIBRAS

\begin{tabular}{lcc} 
& $\begin{array}{c}\text { Subscripción } \\
\text { en París }\end{array}$ & $\begin{array}{c}\text { Participación en } \\
\text { Sindicato de Garantía }\end{array}$ \\
\hline Montant total & 606.0 & 817.0 \\
Groupe BPPB & 168.0 & 192.0 \\
BPPB & 93.4 & 96.0 \\
OB & 22.5 & 73.8 \\
Table & & 22.2 \\
Succursales & 52.1 & 191.0 \\
Groupe A.J.Stern & 143.0 & 192.0 \\
Groupe CNE & 151.0 & \\
CNE & 64.0 & \\
Hentsch & 27.0 & \\
Girod & 20.0 & \\
Thomas & 20.0 & \\
Siegfried & 10.0 & \\
Denfert & 10.0 & \\
Groupe CA & 144.0 & \\
L.et R.CA & 74.8 & \\
Heine & 22.5 & \\
Kohn,Reinach & 15.0 & \\
B.Constantinople & 13.1 & \\
Gunzburg & 7.5 & \\
Betzold & 3.7 & \\
Montefiore & 3.7 & \\
O.Bemberg & & \\
M.Balcarce & & \\
& &
\end{tabular}

Fuente: ABP-Dossiers, 252-4, Cartas a Morton Rose, 13 y 18 de noviembre de 1882. 


\section{CuAdro 4}

GRUPO DE LA BANQUE DE PARIS ET DES PAYS BAS. CUADRO DE INTERESES Y DE ASOCIADOS EN ARGENTINA (1881-1914).

Asociados

en Francia

en Argentina

otros países

\section{A) Empréstitos públicos}

Gobierno argentino

1. Ferrocarriles, 1881

2. Bill.Tesorería, 1882

3. Banco Nacional, 1884

4. Obras Públicas, 1886-7

$\begin{array}{lr}\text { CNE, CA } & \text { BH } \\ \text { CNE, CA } & \text { BH } \\ \text { CNE, CA } & \text { BH } \\ \text { CNE, CA, } & \\ \text { SG, CIC } & \text { BH } \\ \text { CNE, SG, } & \\ \text { CIC } & \text { ET } \\ \text { CNE, SG, } & \\ \text { CIC } & \text { ET } \\ \text { CNE, SG, } & \end{array}$

$\mathrm{BH}$

Murrieta (L)

$\mathrm{BH}$

Morton Rose (L)

$\mathrm{BH}$

Baring Broth. (L)

4. Obras Públicas, 1886-7

$\mathrm{BH}$

Baring Broth.,

5. Adelantos s/letras, 1905

ET

6. Crédito Argentino Interno, 1907

7. Crédito Argentino

Interno, 1909

CIC

DB

J.S.Morgan (L)

Baring Broth.,

J.S.Morgan (L)

ET

Baring, Morgan

(L), D-D (B)

Baring, Morgan

J.P.Morgan (NY)

Gobiernos provinciales

1. Buenos Aires, 1882

CNE, CA

$\mathrm{BH}$

(L), D-D (B),

2. Buenos Aires, 1883

CNE, CA

$\mathrm{BH}$

Morton Rose (L)

3. Santa Fe, 1910

BJ

Portalis

4. Buenos Aires, 1910

BJ

Portalis

Morton Rose (L)

\section{B) Participación en Empresas}

Compañías de ferrocarriles:

$\begin{array}{lll}\text { 1. SCT (1887-1896) } & \text { FL, BRF, } & \text { Portalis } \\ & \text { SFEE, MPV } & \\ \text { 2. NOA (1889-1896) } & \text { Gouin, SCB } & \text { Portalis } \\ \text { 3. FSF (1888-1914) } & \text { FL, BRF, } & \text { Portalis } \\ & \text { SFEE, MPV } & \text { DB-RO (d.1893) } \\ & \text { SG (1905-14) } & \\ \text { 4. GBA (1905-1914) } & \text { BUP, HB } & \text { DB-RO } \\ & & \text { (Br), EB (A) } \\ \text { 5. RPB (1906-1914) } & \text { SG, BJ, SCB, } & \text { DA, OB, } \\ & \text { AJS, OB, HF } & \text { BM }\end{array}$

SGB, Phil., CFS 


\section{CUADRO 4 (continuación)}

Asociados

en Francia

en Argentina

otros países

Compañías de crédito hipotecario:

1. CFSF (1896-1914)

2. CFA (1906-1914) Otras:

1. CGTBA

\section{BRF}

BUP (d.1904)

SG, CNE

CNE
Llambí Campbell

DB, GB, Catelin

ET

SIPBS (A)

SOFINA (Br)

(L) Londres; (B) Berlin; (NY) New York; (Br) Bruxelles; (A) Anvers

Siglas: AJS, A.J.Stern et Cie.; BH, Bemberg, Heimendahl et Cie.; BJ, Bénard et Jarislowsky; BM, Bustos Morón; BPPB, Banque de Paris et des Pays Bas; BRF, Banque Russe et Française; BUP, Banque de l'Union Parisienne; CA, L. et R.Cahen d'Anvers; CFS, Compagnie Générale des Chemins de Fer Secondaires; CIC, Crédit Industriel et Commercial; CNE, Comptoir National d'Escompte; DA, Diego de Alvear; D-D, Deutsche Bank et Diskonto Bank; DB, C. De Bruyn; EB, Edouard Bunge et Cie.; ET, Ernesto Tornquist et Cie.; FL, Compagnie Fives Lille; GB, Georges Born; HB, Haute Banque (De Neuflize, Mallet, Mirabaud, Vernes, Hottinguer, Heine); HF, Hersent Frères; MPV, Mirabaud, Puerari et Vernes; OB, Otto Bemberg et Cie.; Phil, Phillipson et Cie.,; RO, Rómulo Otamendi; SFEE, Société Française d'Etudes et Entreprises; SG, Société Générale, y SGB, Société Générale de Belgique. 